\title{
Жизненный опыт как потенциал успешного старения
}

\author{
Жанна М. Глозман ${ }^{1 *}$, Валентина А. Наумова \\ ${ }^{1}$ Московский государственный университет имени М.В. Ломоносова, г. Москва, \\ Российская Федерация \\ ${ }^{2}$ Камчатский государственный университет имени Витуса Беринга, г. Петропавловск- \\ Камчатский, Российская Федерация \\ *E-mail: glozman@mail.ru
}

\begin{abstract}
Аннотация
Ввеление. Авторами обосновывается актуальность исследования в связи с изменением современной Аемографической ситуации и необхолимостью поиска психологических возможностей формирования позитивного образа старости. На основании анализа публикаций конкретизируется определение успешного старения. Цель исследования заключается в анализе значения сохранности жизненных ресурсов как важного условия мобилизации потенциала успешного старения. В качестве обоснования ^огики эмпирической части представлен рял теоретических предпосылок, объединенных вытеснением Аоминирования инволюционной параАигмы старения и полноправным принятием парадигмы успешного старения. Новизна исследования заключается в том, что показана роль целенаправленно организованной творческой Аеятельности в реализации потенциального жизненного опыта Аля подАержания успешного старения.
\end{abstract}

Методы. В разделе представлена характеристика испытуемых - 130 человек в возрасте от 56 Ао 84 ^ет, проживающих на территории Камчатского края. Описываются методики: экспресс-методика оценки когнитивных функций при нормальном старении (Н.К. Корсакова, Е.Ю. Балашова, И. Ф. Рощина); тест жизнестойкости S.R. Maddi, S. Kobasa (адаптация А. А. Аеонтьева, Е.И. Рассказовой); шкала психологического благополучия К. Рифрф (аАаптация Т.А. Шевеленковой, Т.П. Фесенко); анкета «Субъективное восприятие своей жизни» (Е. Н. Чуева, В. А. Наумова). Представлен Аизайн исследования.

Результаты. В Аанном разделе приводятся результаты эмпирического исслеАования эорорективности участия старого человека в целенаправленно организованной Аеятельности в арт-группе Аля реализации потенциала успешного старения. Аоказано, что сохранение когнитивного ресурса и саморегулирующих способностей ^ичности в старости - это условие актуализации потенциального жизненного опыта.

ОбсужАение результатов. Рассматривается значение реализации жизненного опыта в старости как субъекта своей жизнеАеятельности и возможной позитивной 
КОГНИТИВНАЯ ПСИХОЛОГИЯ

жизненной перспективы. Анализируются причины, затрудняющие использование жизненного опыта как потенциала успешного старения.

\title{
КАючевые слова
}

успешное старение, жизненный опыт, когнитивный ресурс, жизнестойкость, субъект жизнелеятельности, арт-терапия, реализация потенциала, жизненная перспектива, образ старения, психологическое благополучие

\section{Основные положения}

- жизненный опыт в старости при наличии определенных условий и фракторов является потенциалом успешного старения;

- сохранение когнитивного ресурса и саморегулирующих способностей ^ичности в старости выступает условием актуализации потенциального жизненного опыта; - специально организованная целенаправленная деятельность выступает детерминирующим орактором реализации потенциала успешного старения.

\section{Для цитирования}

Глозман Ж. М., Наумова В.А. Жизненный опыт как потенциал успешного старения // Российский психологический журнал. 2018. Т. 15, № 3. С. 25-51. DOI: 10.21702/ rpj.2018.3.2

\section{Life Experience as a Potential for Successful Ageing}

\author{
Zhanna M. Glozman ${ }^{*}$, Valentina A. Naumova² \\ ${ }^{1}$ Lomonosov Moscow State University, Moscow, Russian Federation \\ ${ }^{2}$ Vitus Bering Kamchatka State University, Petropavlovsk-Kamchatsky, Russian Federation \\ ${ }^{*}$ Corresponding author. E-mail: glozman@mail.ru
}

\begin{abstract}
Introduction. It is necessary to look for psychological opportunities for forming a positive image of old age under the undergoing changes in demographic conditions of the modern society. Based on their overview of previous publications, the authors concretize the definition of successful aging. This study attempts to analyze the importance of preserving one's life resources in mobilizing the potential for successful ageing. The empirical study rests on certain theoretical prerequisites that all agree on the need to replace the involutional paradigm of aging with the paradigm of successful aging.
\end{abstract}


The authors demonstrate the role of a purposeful creative activity for the realization of a potential life experience in the process of maintaining successful aging.

Methods. The following methods were used: (a) the technique for rapid assessment of cognitive functions in normal aging (N.K. Korsakova, E. Yu. Balashova, I.F. Roshchina); (b) Hardiness Survey by S.R. Maddi and S. Kobasa (adaptation of D. A. Leont'ev and E.I. Rasskazova); (c) K. Ryff's Scales of Psychological Well-being (adaptation of T.D. Shevelenkova and T.P. Fesenko); and (d) the Subjective Perception of Own Life questionnaire (E.N. Chueva, V.A. Naumova). The sample comprised 130 respondents aged 56-84 years living in the territory of Kamchatka.

Results. This section reports the empirical results concerning the effectiveness of elderly adults' participation in purposeful activities in the art group. It is proved that the preservation of individuals' cognitive resources and self-regulating abilities in old age is a condition for actualization of their potential life experience.

Discussion. The realization of life experience in old age determines positive life perspectives. The authors analyze the reasons that may complicate the realization of life experience as a potential for successful aging.

\section{Keywords}

successful aging, life experience, cognitive resource, vitality, subject of life activity, art therapy, realization of potential, life perspective, image of aging, psychological well-being

\section{Highlights}

- Under certain conditions life experience in old age is a potential for successful aging.

- The preservation of individuals' cognitive resources and self-regulating abilities in old age is a condition for actualization of their potential life experience.

- Purposeful activity determines the realization of the potential for successful aging.

\section{For citation}

Glozman Z.M., Naumova V. A. Life Experience as a Potential for Successful Ageing. Rossiiskii psikhologicheskii zhurnal - Russian Psychological Journal, 2018, V. 15, no. 3, pp. 25-51 (in Russian). DOI: 10.21702/rpj.2018.3.2

Original manuscript received 07.07.2018

\section{Введение}

Актуальность настоящего исследования обусловлена рядом причин. Вопервых, глобальные изменения современной демографической ситуации, выражающиеся в увеличении продолжительности жизни человека и феномене «стареющего населения» [1, с. 6], объясняют возрастающую потребность 
концептуальной проработки проблемы старения и поиска новых стратегий, программ, моделей обеспечения (сопровождения) благополучия в старости.

Вторая группа причин связана с тем, что большое число публикаций за последнее десятилетие оценивает многие негативные стереотипы старения только через призму противопоставления предыдущего периода онтогенеза, где эталоном (критерием) выступает период взрослости. Это объясняется дефицитом валидизированных методов исследования пожилого и более старшего поколения, учитывающих особенности и уникальность онтогенетического периода старости - длительного, многокомпонентного, противоречивого, обладающего индивидуальностью и высоким уровнем вариативности $[2,3,4,5,6]$.

В третьей группе причин мы рассматриваем успехи современной геронтопсихологии, нейрогеронтопсихологии, геронтопсихиатрии и психологии развития, благодаря которым происходит вытеснение доминирования инволюционной парадигмы старения и полноправное принятие парадигмы успешного старения [7].

Понятие «успешное старение» ввел R.J. Havighurst еще в 1961 г., характеризуя его как состояние стареющего человека, в котором он переживает удовлетворенность от жизни без значимых затрат для общества. В основе предложенного варианта старения ученый рассматривал переживание внутреннего чувства счастья, удовлетворенность настоящим и прошлым и также мудрость [8]. И только результаты многолетнего масштабного американского проекта, организованного в 1998 г. фондом Джона и Кэтрин МакАртуров, возглавляемого Д. Роуи и Р. Каном, послужили платформой для официального введения нового направления в геронтопсихологии - «успешного» старения [9, $10,11,12]$. Исследователи, опираясь на позитивные аспекты функционирования старения, пришли к выводу о том, что старость, как и предыдущие этапы онтогенеза, может быть наполненной смыслами и довольно высокопродуктивной. Однако на сегодняшний день среди ученых нет единогласно принятого определения данного концепта, и в публикациях довольно много близких по содержанию терминов: счастливое [13, 14], активное [15, 16], здоровое [17], конструктивное [18, 19, 20], благополучное [21], позитивноконструктивное $[22,23,24]$ старение и др.

Вероятно поэтому в современной литературе сохраняется проблема конкретизации дефиниций успешного старения как процесса или результата развития личности на этапе позднего онтогенеза.

Нами предпринята попытка рассматривать успешное старение с позиции актуализации и реализации возможностей потенциала жизненного опыта, позволяющего продуктивно функционировать стареющему человеку как субъекту собственной жизнедеятельности [4, 20]. 
Ряд исследователей отмечает, что жизненный опыт является специфическим ресурсом старения. Вслед за Д.А. Леонтьевым [25] под понятием ресурсы мы рассматриваем средства, наличие и достаточность которых способствуют достижению цели. В результате прохождения личностью определенного жизненного пути прижизненно формируется совокупность особенностей личности, как следствие проживания собственного опыта самопознания, самоосознания, саморегуляции, самодетерминации, самопрезентации и самоорганизации [3, 25, 26, 27].

Важно, что индивидуальность и уникальность жизненного опыта обеспечивается не конкретными ситуациями и событиями, в которых участвовал человек в течение своей жизни, а скорее кумуляцией и селекцией опыта, их когнитивного оценивания и эмоционального переживания (проживания). Это обусловливает накопление определенных стратегий обработки информации, что, по сути, представляет когнитивный ресурс, сохранность и мобильность которого является важным средством обеспечения качества жизни старых людей $[28,29]$. Жизненный опыт при этом является смыслообразующей структурой личности, детерминирующей ее развитие на этапах позднего онтогенеза [30, 31, 32, 33]. В то же время можно отметить, что исчерпать всё многообразие индивидуального опыта собственной жизни крайне сложно и порой проблематично. Важно, что вклад невостребованного опыта на этапе старения зависит от сохранения «способностей использовать свои способности» [25, с. 22] к самодетерминированному выбору и автономной субъектной активности, адаптивной устойчивости к воздействиям внешних обстоятельств и открытости новому, позитивного отношения к себе как к ценности, что в целом соответствует описанию психологических ресурсов саморегуляции [34, 35, 36].

Данный факт дает основание сформулировать цель исследования - поиск условий и факторов актуализации жизненного опыта как потенциала успешного старения.

Предпосылками настоящего исследования послужили несколько положений:

- в период позднего онтогенеза, на фоне сохранных способов психической самоактивности, снижается функционирование блока потребности и способности к выбору и реализации целей своего психического развития [31];

- при нормальном старении отмечается относительная сохранность параметров деятельности, обеспечиваемых структурно-функциональным блоком программирования и контроля [37];

в в старости сохранная способность к высокой творческой продуктивности стимулирует личность варьировать как реальным, так и потенциальным жизненным опытом [38]. 
КОГНИТИВНАЯ ПСИХОЛОГИЯ

Мы предположили, что сохранные когнитивный ресурс и саморегулирующие способности пожилого и старого человека выступают условием актуализации потенциала жизненного опыта, способствующего адаптивному структурированию жизнедеятельности.

Организованный процесс целенаправленной деятельности выступает детерминирующим фактором реализации потенциалов жизненного опыта и поддержания благополучия успешного старения.

\section{Методы}

Группу испытуемых составили жители п. Оссора Камчатского края и г. Петропавловска-Камчатского в количестве 130 человек в возрасте от 56 до 84 лет (рисунок 1). Все участники группы на этапах исследования были соматически компенсированы, выраженных расстройств личности и поведения не имели.

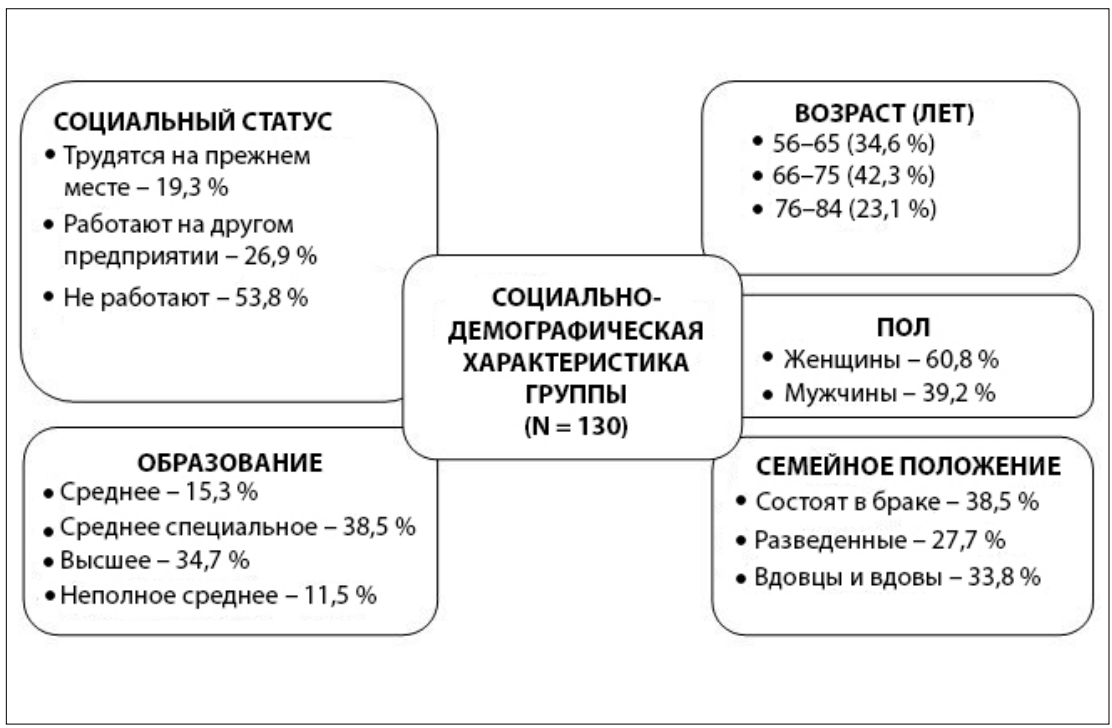

Рисунок 1. Подробная социально-лемографическая характеристика исследовательской группы

Figure 1. Socio-demographic characteristics of the study sample

Больший процент официально не работающих респондентов отчасти обусловлен региональной спецификой: законодательный выход на пенсию в Камчатском крае у женщин в 50 лет, мужчин - в 55 лет. 


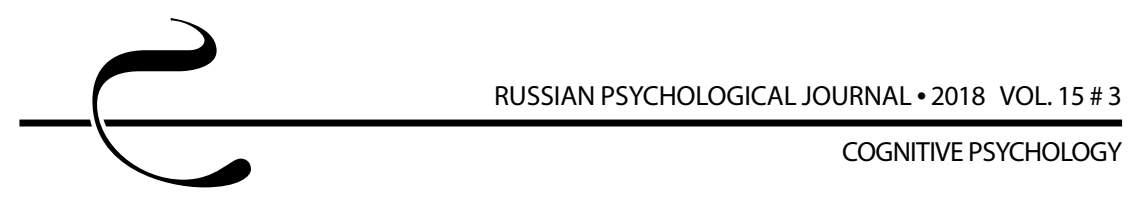

\section{Методики исследования:}

1. Экспресс-методика оценки когнитивных функций при нормальном старении (Н.К. Корсакова, Е.Ю. Балашова, И. Ф. Рощина, 2009 г.), направленная преимущественно на исследование разных аспектов мнестической и интеллектуальной деятельности, с позиции структурно-функциональной модели мозга А.Р. Лурия [37].

2. Тест жизнестойкости S. R. Maddi, S. Kobasa (адаnтачия Д. А. Леонтьева, Е.И. Рассказовой, 2006 г.) позволяет исследовать личностные особенности испытуемых (включенность, контроль, принятие риска) как систему установок о себе, мире и отношений с ним, с точки зрения сохранных ресурсных способностей самостоятельно репрезентировать устойчивые саморегулируемые стратегии [39].

3. Шкала психологического благополучия К. Рифф (адаптачия Т.Д. Шевеленковой, Т.П. Фесенко), направленная на диагностику особенностей субъективного самоощущения целости и осмысленности бытия стареющего человека, что, в общем, позволяет оценить и проанализировать актуальное психологическое благополучие респондентов [40].

4. Анкета «Субъективное восприятие своей жизни» (Е. Н. Чуева, 2005 г.; модификация В.А. Наумовой, 2014 г.) содержит показатели субъективной удовлетворенности уровнем личностной активности, состоянием здоровья и принятием возраста $[18,20]$.

\section{Дизайн исследования}

На первом (констатирующем) этапе исследования анализировались результаты диагностики когнитивного ресурса (экспресс-методика), сохранности саморегулирующих способностей (компоненты жизнестойкости) и оценки состояния актуального психологического благополучия.

Для анализа особенностей психических процессов вслед за авторами экспресс-методики [37] были сформированы три возрастных подгруппы: 1) 45 респондентов от 56 до 65 лет (средний возраст - 61,8 года); 2) 55 респондентов от 66 до 75 лет (средний возраст - 69,5 года); 3) 30 респондентов от 76 до 84 лет (средний возраст - 78,9 года).

Из таблицы 1 видно, что в разных заданиях снижение показателей распределено неравномерно. Так, выраженные разрывы в баллах обнаружены в заданиях, связанных с работой третьего структурного функционального блока. В заданиях на запоминание и анализ организованного по смыслу материала разброс средних оценок составил от 0,1 до 0,4, что совпадает с анализом авторов экспресс-методики [37]. Объединяя выше представленные данные и учитывая результаты наших предыдущих исследований $[4,20]$, мы можем рассматривать относительную сохранность этих параметров 
КОГНИТИВНАЯ ПСИХОЛОГИЯ

деятельности как вероятный ресурс когнитивных функций при нормальном старении. Однако достоверных различий по показателям экспресс-методики в возрастных подгруппах не было обнаружено, и в связи с этим анализ дальнейших диагностических параметров проводился в целом по выборке.

Таблица 1. Средние оценки выполнения заланий экспресс-метолики в подгруп$\operatorname{nax}(б а \wedge \wedge ы)$

Table 1. Fulfillment of tasks of the technique for rapid assessment in subgroups (mean scores)

\begin{tabular}{|c|c|c|c|c|}
\hline $\begin{array}{c}\text { Залания } \\
\text { Tasks }\end{array}$ & $\begin{array}{c}56-65 \wedge е т \\
56-65 \text { years } \\
(n=45)\end{array}$ & $\begin{array}{c}\text { 66-75 ^ет } \\
66-75 \text { years } \\
(n=55)\end{array}$ & $\begin{array}{c}76-84 \wedge е т \\
76-84 \text { years } \\
(n=30)\end{array}$ & $\begin{array}{c}\text { Группа в целом } \\
\text { Group (total) } \\
\text { (n = 130) }\end{array}$ \\
\hline 1 & 0,5 & 0,9 & 1,4 & 0,9 \\
\hline 2 & 0,3 & 0,4 & 1,1 & 0,6 \\
\hline 3 & 0,4 & 0,7 & 0,8 & 0,6 \\
\hline 4 & 0,9 & 1,1 & 1,4 & 1,3 \\
\hline 5 & 3,5 & 4,5 & 5,4 & 4,7 \\
\hline 6 & 0,7 & 0,8 & 1 & 0,8 \\
\hline 7 & 0,3 & 0,3 & 0,4 & 0,3 \\
\hline 8 & 1 & 1,5 & 1,7 & 1,4 \\
\hline 9 & 0,1 & 0,4 & 0,5 & 0,3 \\
\hline 10 & 0,2 & 0,4 & 0,5 & 0,4 \\
\hline 11 & 0,3 & 0 & 0 & 0,1 \\
\hline 12 & 0 & 0,1 & 0 & 0 \\
\hline $\begin{array}{l}\text { Общий ба^^ } \\
\text { Overall score }\end{array}$ & 8,2 & 11,1 & 14.2 & 11,3 \\
\hline
\end{tabular}

Результаты данных исследования теста жизнестойкости представлены в таблице 2 .

Данные таблицы 2 фиксируют, что в целом по выборке показатели соответствуют нижнему порогу средних значений (по нормативам Д. А. Леонтьева, Е.И. Рассказовой, 2006 г.), - это, в принципе, позволяет оценить их соответствие условной функциональности. Однако обращает на себя внимание результат сравнительного анализа процентного распределения нормативных показателей компонентов жизнестойкости, который позволяет установить их качественные особенности (таблица 3). 
Таблица 2. Показатели компонентов жизнестойкости (констатирующий этап)

Table 2. Components of vitality (ascertaining stage)

\begin{tabular}{|l|c|c|c|}
\hline \multicolumn{1}{|c|}{$\begin{array}{c}\text { Шкалы } \\
\text { Scales }\end{array}$} & $\begin{array}{c}\text { Срелние } \\
\text { значения } \\
\text { Mean scores }\end{array}$ & $\begin{array}{c}\text { Стандартное } \\
\text { отклонение } \\
\text { Standard } \\
\text { deviation }\end{array}$ & $\begin{array}{c}\text { Аисперсия } \\
\text { Dispersion }\end{array}$ \\
\hline $\begin{array}{l}\text { Жизнестойкость } \\
\text { Vitalitу }\end{array}$ & 62,3 & 17,4 & 137,8 \\
\hline $\begin{array}{l}\text { Вовлеченность } \\
\text { Involveтепт }\end{array}$ & 30,91 & 7,9 & 66,0 \\
\hline $\begin{array}{l}\text { Контроль } \\
\text { Соntrol }\end{array}$ & 21,0 & 8,8 & 77,5 \\
\hline $\begin{array}{l}\text { Принятие риска } \\
\text { Risk taking }\end{array}$ & 10,2 & 5,3 & 21,1 \\
\hline
\end{tabular}

Таблица 3. Распрелеление показателей компонентов жизнестойкости

Table 3. Distribution of scores of vitality components

\begin{tabular}{|c|c|c|c|c|c|c|c|c|}
\hline \multirow{2}{*}{$\begin{array}{c}\text { Уровень } \\
\text { значений } \\
\text { Level }\end{array}$} & \multicolumn{2}{|c|}{$\begin{array}{c}\text { Жизне- } \\
\text { стойкость } \\
\text { Vitality }\end{array}$} & \multicolumn{2}{|c|}{$\begin{array}{c}\text { Вовле- } \\
\text { ченность } \\
\text { Involvement }\end{array}$} & \multicolumn{2}{|c|}{$\begin{array}{c}\text { Контромь } \\
\text { Control }\end{array}$} & \multicolumn{2}{|c|}{$\begin{array}{l}\text { Принятие } \\
\text { риска } \\
\text { Risk taking }\end{array}$} \\
\hline & $\begin{array}{c}\text { KON- } \\
\text { BO } \\
\text { N }\end{array}$ & $\%$ & $\begin{array}{c}\text { Кол- } \\
\text { BO } \\
\text { N }\end{array}$ & $\%$ & $\begin{array}{c}\text { Kол- } \\
\text { BO } \\
\text { N }\end{array}$ & $\%$ & $\begin{array}{c}\text { Kon- } \\
\text { BO } \\
\text { N }\end{array}$ & $\%$ \\
\hline $\begin{array}{l}\text { Высокие } \\
\text { значения } \\
\text { High }\end{array}$ & 15 & 11,5 & 11 & 8,5 & 25 & 19,2 & 25 & 19,2 \\
\hline $\begin{array}{l}\text { Средние } \\
\text { значения } \\
\text { Average }\end{array}$ & 90 & 69,3 & 95 & 73,1 & 60 & 46,2 & 40 & 30,8 \\
\hline $\begin{array}{l}\text { Низкие } \\
\text { значения } \\
\text { Low }\end{array}$ & 25 & 19,2 & 24 & 18,4 & 45 & 34,6 & 65 & 50,0 \\
\hline
\end{tabular}


Так, из таблицы 3 видно, что частый выбор респондентами средних значений по шкалам «общая жизнестойкость» / «вовлеченность», свидетельствующий об их личностной активности в решении обязательных жизненных задач, сочетается с предпочтением выбора низких значений по шкалам «контроль» и «принятие риска». Возникшее противоречие усиливается результатами контент-анализа описаний субъективного восприятия личностной активности и самопринятия (по анкете «Субъективное восприятие своей жизни»), свидетельствующими о тенденции большинства участников к состоянию жизненной пассивности, ощущению у себя «вынужденности к доживанию старой жизнью» и убежденности в том, что они мало интересны настоящему происходящему, а современные достижения цивилизации уже мало способствуют их развитию и движению. Так, например, на вопрос «Изменилось ли восприятие времени?» были ответы (здесь и далее приведенные примеры ответов респондентов даны в авторском изложении. - Прим. aвm.): «сплошные одинаковые серые дни»; «не жизнь, а день Сурка, ничего не тормошит меня»; «живу только прошлым; «понятно, что хорошая жизнь прошла и скоро совсем всё закончится». Ответы на другой вопрос: «Что для Вас жизненное счастье?» - «счастье детей», «жить ради детей», «отсутствие болей и доброта врачей», «всю жизнь работала без отдыха, а теперь пусть все ухаживают за мной», "сохранение терпимых отношений с родственниками», «скучное ковыряние на даче, да уже и тяжело лопатой-то...», «ой, какое счастье? Всё уже раздражает, совсем приелась в жизни, а новое мне не "по зубам", страшно подумать, как с этим жить-то...».

Далее мы проанализировали состояние актуального психологического благополучия испытуемых (таблица 4).

Таблица 4. Показатели компонентов психологического благополучия

Table 4. Components of psychological well-being

\begin{tabular}{|c|c|c|c|}
\hline $\begin{array}{l}\text { Шкалы } \\
\text { Scales }\end{array}$ & $\begin{array}{c}\text { Средние } \\
\text { значения } \\
\text { Mean scores }\end{array}$ & $\begin{array}{c}\text { Стандартное } \\
\text { откмонение } \\
\text { Standard } \\
\text { deviation }\end{array}$ & $\begin{array}{c}\text { Аисперсия } \\
\text { Dispersion }\end{array}$ \\
\hline $\begin{array}{l}\text { Позитивные отношения } \\
\text { с окружающими } \\
\text { Positive relations with others }\end{array}$ & 54,80 & 7,36 & 135,2 \\
\hline $\begin{array}{l}\text { Автономия } \\
\text { Autonomy }\end{array}$ & 52,55 & 7,34 & 60,1 \\
\hline $\begin{array}{l}\text { Управление срелой } \\
\text { Managing the environment }\end{array}$ & 53,92 & 7,13 & 90,4 \\
\hline
\end{tabular}




\begin{tabular}{|l|c|c|c|}
\hline \multicolumn{1}{|c|}{$\begin{array}{c}\text { Шкалы } \\
\text { Scales }\end{array}$} & $\begin{array}{c}\text { Средние } \\
\text { значения } \\
\text { Меan scores }\end{array}$ & $\begin{array}{c}\text { Стандартное } \\
\text { отклонение } \\
\text { Standard } \\
\text { deviation }\end{array}$ & $\begin{array}{c}\text { Аисперсия } \\
\text { Dispersion }\end{array}$ \\
\hline $\begin{array}{l}\text { Аичностный рост } \\
\text { Personal growth }\end{array}$ & 55,83 & 6,10 & 30,2 \\
\hline $\begin{array}{l}\text { Цель в жизни } \\
\text { Purpose in life }\end{array}$ & 58,02 & 8,89 & 49,4 \\
\hline $\begin{array}{l}\text { Caмопринятие } \\
\text { Self-ассерtance }\end{array}$ & 52,73 & 8,50 & 66,8 \\
\hline
\end{tabular}

Полученный анализ данных также свидетельствует о соответствии их нижней границе средних значений (по нормативам Т.Д. Шевеленковой, Т.П. Фесенко, 2005 г.). Проведенный корреляционный анализ между показателями параметров шкал жизнестойкости и психологического благополучия подтверждает, что субъективное благополучие участников исследовательской группы во многом определяется реакцией среды и оценкой Другого; также отмечается тенденция к обеднению жизненных целей, планов, к снижению личностной значимости и самоценности (рисунок 2).

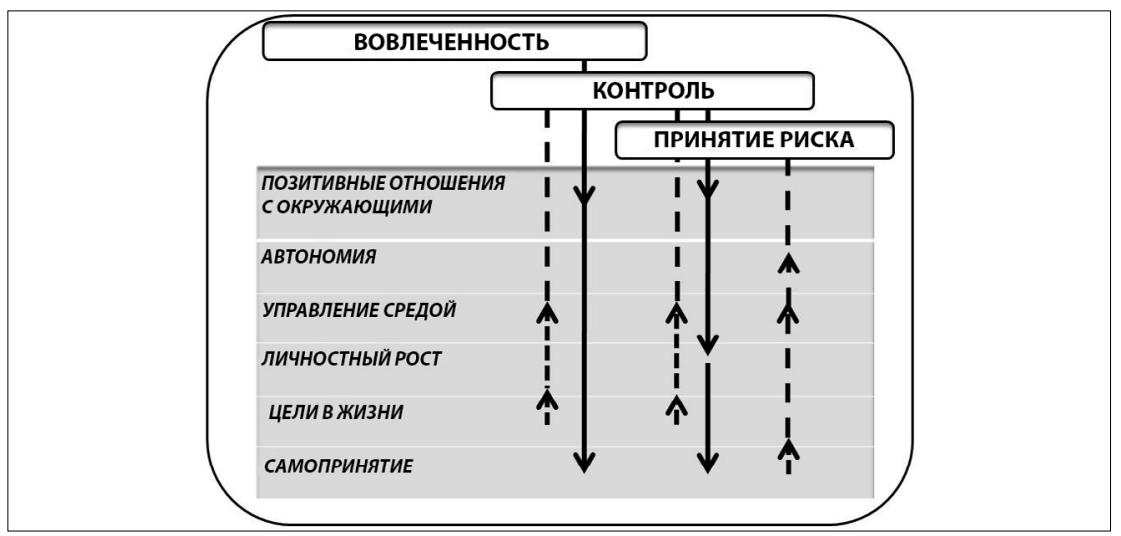

Рисунок 2. Схема результата корреляционного анализа межАу компонентами жизнестойкости и психологического благополучия на констатирующем этапе

Условные обозначения: $\downarrow$ - положительная коррелячионная связь, $\uparrow$ - отрицательная корреляционная связь.

Figure 2. Scheme of the result of correlation analysis between the components of vitality and psychological well-being at the ascertaining stage 
Резюмируя анализ корреляционных связей и представленный выше исследовательский материал, мы можем утверждать, что демонстрация высокой степени ограничения личностной активности указывает на принятие респондентами реальной жизненной ситуации развития-вынужденной (состоявшейся), но неудовлетворяющей. Пытаясь объяснить полученный факт, можно обратиться к специфичности вынужденного проживания респондентов на этапе позднего онтогенеза в Камчатском регионе на фоне современной экономической ситуации. Традиционно, много десятилетий в советское время в регионе сохранялся «преимущественно вахтовый стиль» проживания через призму «хорошо обеспеченного будущего», но вследствие экономических кризисов данная схема утратила значимость. В результате человек, проработав «молодые годы до пенсии» в ситуации территориальной отдаленности и тяжелых природно-климатических условий, вынужден окончательно признать и принять нереализованность планов по обеспечению старости «обязательно на материке» и продолжать свой жизненный путь, лишенный предыдущей трудовой деятельности, в довольно сложной психосоциальной атмосфере.

Bmopoŭ эman в дизайне нашего исследования заключался в разработке и реализации программы психологической интервенции творческими методами системной арт-терапии [41]. Мы использовали возможности тематической арт-группы, полагая, что целенаправленная, интерактивная творческая деятельность, адекватная и безопасная коммуникация стимулируют опосредованность переживания участников реального происходящего и запускает механизм актуализации и реализации жизненного опыта как потенциального (ранее не востребованного) [41, 42].

Комплектация техник и технологий осуществлялась с опорой на сохранные звенья психической деятельности с учетом выявленных у респондентов снижений когнитивных функций: замедления темпа деятельности, трудностей переключения и распределения внимания, увеличения периода включения в выполнение заданий, снижения помехоустойчивости в переработке информации, сложностей реализации пространственных задач. В целом занятия включали: графические техники с вербальным сопровождением или музыкальным компонентом («Линия жизни», «Грани моего Я», «Коллаж жизни», «Автопортрет» и др.), приемы изобразительной стимуляции когнитивных навыков и межличностных взаимодействий (составление арт-дневника; арт-техники в сочетании с драмой, поэзией, музыкой и танцами; парная работа с пословицами и афоризмами и др.), техники творческого самовыражения, поиска и раскрытия ресурсов саморегуляции (фото- и музыкотерапия, тематические инсталляции и перформанс, ландшафная арт-терапия, телесноориентированная арт-терапия и др.) [43, 44, 45]. Программа реализовывалась 
в течение 12 месяцев с частотой два раза в неделю по два часа, а также по желанию участников, предлагались домашние задания [4].

\section{Результаты}

Многие исследователи отмечают, что систематическое погружение в тематический, интеракционный творческий процесс позволяет человеку в период старения реабилитировать осознание наличия собственных психологических особенностей, способов их трансформации и презентации для более успешного функционирования в действительности $[41,44,45]$.

Подтверждением этих наблюдений являются показатели по шкалам компонентов жизнестойкости на 3-м контрольном этапе исследования (таблица 5).

Таблица 5. Аинамики показателей компонентов жизнестойкости (контрольный срез)

Table 5. Dynamics of values of vitality components (control section)

\begin{tabular}{|c|c|c|c|c|c|c|c|}
\hline \multirow[b]{2}{*}{$\begin{array}{c}\text { Шкалы } \\
\text { теста } \\
\text { Test } \\
\text { scales }\end{array}$} & \multicolumn{3}{|c|}{$\begin{array}{c}\text { Констатирующие } \\
\text { показатели } \\
\text { Ascertaining scores }\end{array}$} & \multicolumn{3}{|c|}{$\begin{array}{c}\text { Контрольные } \\
\text { показатели } \\
\text { Control scores }\end{array}$} & \multirow{2}{*}{$\begin{array}{c}\text { Коэфф. } \\
t \\
\text { Coeffi- } \\
\text { cient } t\end{array}$} \\
\hline & $\begin{array}{l}\text { Cp. } \\
\text { знач. } \\
\text { Mean } \\
\text { scores }\end{array}$ & $\begin{array}{c}\text { Ст. } \\
\text { откА. } \\
\text { Stan- } \\
\text { dard } \\
\text { devia- } \\
\text { tion }\end{array}$ & $\begin{array}{l}\text { Аисп. } \\
\text { Disper- } \\
\text { sion }\end{array}$ & $\begin{array}{l}\text { Cp. } \\
\text { знач. } \\
\text { Mean } \\
\text { scores }\end{array}$ & $\begin{array}{l}\text { Ст. } \\
\text { откА. } \\
\text { Stan- } \\
\text { dard } \\
\text { devi- } \\
\text { ation }\end{array}$ & $\begin{array}{l}\text { Аисп. } \\
\text { Disper- } \\
\text { sion }\end{array}$ & \\
\hline $\begin{array}{l}\text { Жизне- } \\
\text { стойкость } \\
\text { Vitality }\end{array}$ & 62,3 & 17,4 & 257,8 & 78,4 & 15,8 & 261,5 & $3,35^{* *}$ \\
\hline $\begin{array}{l}\text { Вовлечен- } \\
\text { ность } \\
\text { Involve- } \\
\text { ment }\end{array}$ & 30,91 & 7,9 & 66,0 & 40,95 & 5,53 & 50,7 & $3,49 * *$ \\
\hline $\begin{array}{l}\text { Контро^ь } \\
\text { Control }\end{array}$ & 21,0 & 8,8 & 77,5 & 25,5 & 7,06 & 53,7 & $2,13^{*}$ \\
\hline $\begin{array}{l}\text { Принятие } \\
\text { риска } \\
\text { Risk taking }\end{array}$ & 10,2 & 5,3 & 21,1 & 13,8 & 4,7 & 19,5 & $3,15^{*}$ \\
\hline
\end{tabular}


Из таблицы 5 видно, что в целом по выборке показатели контрольного среза входят в параметры верхних границ среднего уровня. Анализ свидетельствует о достоверно значимых различиях по всем шкалам теста.

Анализ результатов динамики распределения показателей компонентов жизнестойкости на контрольном этапе подтверждает эти результаты (таблица 6). Представленная динамика параметров компонентов жизнестойкости подтверждает, что организованная, комфортная и безопасная возможность для пожилого и старого человека быть равноправным участником творческого процесса запускает трансформационные механизмы сличения вероятностных и реальных индивидуальных потребностей, что в свою очередь способствует реальному достижению удовлетворения от собственных действий и происходящих вокруг событий и жизни в целом.

Таблица 6. Аинамика распределения показателей компонентов жизнестойкости

Table 6. Dynamics of distribution of scores of vitality components

\begin{tabular}{|c|c|c|c|c|c|c|c|c|}
\hline \multirow{2}{*}{$\begin{array}{c}\text { Уровень } \\
\text { значений } \\
\text { Level }\end{array}$} & \multicolumn{2}{|c|}{$\begin{array}{l}\text { Жизне- } \\
\text { стойкость } \\
\text { Vitality }\end{array}$} & \multicolumn{2}{|c|}{$\begin{array}{c}\text { Вовлечен- } \\
\text { ность } \\
\text { Involvement }\end{array}$} & \multicolumn{2}{|c|}{$\begin{array}{c}\text { Контроль } \\
\text { Control }\end{array}$} & \multicolumn{2}{|c|}{$\begin{array}{c}\text { Принятие } \\
\text { риска } \\
\text { Risk taking }\end{array}$} \\
\hline & $\begin{array}{c}\text { KOn- } \\
\text { BO } \\
\text { N }\end{array}$ & $\%$ & $\begin{array}{c}\text { Kon- } \\
\text { BO } \\
\mathrm{N} \\
\end{array}$ & $\%$ & $\begin{array}{c}\text { Kon- } \\
\text { BO } \\
\mathrm{N} \\
\end{array}$ & $\%$ & $\begin{array}{c}\text { KOn- } \\
\text { BO } \\
\text { N }\end{array}$ & $\%$ \\
\hline $\begin{array}{l}\text { Высокие } \\
\text { значения } \\
\text { High }\end{array}$ & 22 & 16,9 & 18 & 13,8 & 19 & 14,6 & 18 & 13,8 \\
\hline $\begin{array}{l}\text { Средние } \\
\text { значения } \\
\text { Average }\end{array}$ & 94 & 72,4 & 102 & 78,5 & 86 & 66,2 & 82 & 63,1 \\
\hline $\begin{array}{l}\text { Низкие } \\
\text { значения } \\
\text { Low }\end{array}$ & 14 & 10,7 & 10 & 7,7 & 25 & 19,2 & 30 & 23,1 \\
\hline
\end{tabular}

Достоверно значимые различия по шкале «контроль» $(p \leq 0,05)$ показывают тенденцию респондентов к активному поиску путей влияния и противостояния негативным, довольно часто стрессогенным, возрастным изменениям и важность самостоятельного выбора деятельности и адекватных стратегий жизнедеятельности в старости. Рост показателей по шкале «принятие риска» $(p \leq 0,05)$ репрезентирует возросшую потребность использовать знания из приобретенного (часто невостребованного) на предыдущих этапах жизни опыта для осознания и принятия жизненной компетентности в реальной действительности. 
Сравнительный анализ компонентов психологического благополучия фиксирует достоверно значимые различия по всем шкалам (таблица 7).

Из таблицы 7 видно, что на контрольном этапе появились показатели, соответствующие высокому уровню (компоненты «автономия» и «управление средой»). Важно отметить, что показатели других компонентов в целом соответствуют верхним границам всё же средних параметров.

таблица 7. Аинамика показателей по шкалам психологического благополучия

Table 7. Dynamics of scores for scales of psychological well-being

\begin{tabular}{|c|c|c|c|c|c|c|c|}
\hline \multirow[b]{2}{*}{$\begin{array}{c}\text { Шкалы теста } \\
\text { Test scales }\end{array}$} & \multicolumn{3}{|c|}{$\begin{array}{c}\text { Констатирующие } \\
\text { показатели } \\
\text { Ascertaining scores }\end{array}$} & \multicolumn{3}{|c|}{$\begin{array}{c}\text { Контрольные } \\
\text { показатели } \\
\text { Control scores }\end{array}$} & \multirow[b]{2}{*}{$\begin{array}{c}\text { Коэффф. } \\
t \\
\text { Coeffi- } \\
\text { cient } t\end{array}$} \\
\hline & $\begin{array}{l}\text { Cp. } \\
\text { 3HOr. } \\
\text { Mean } \\
\text { scores }\end{array}$ & $\begin{array}{l}\text { CT. } \\
\text { откג. } \\
\text { Stan- } \\
\text { dard } \\
\text { devi- } \\
\text { ation }\end{array}$ & $\begin{array}{l}\text { Aисn. } \\
\text { Disper- } \\
\text { sion }\end{array}$ & $\begin{array}{l}\text { Cp. } \\
\text { знач. } \\
\text { Mean } \\
\text { scores }\end{array}$ & $\begin{array}{l}\text { Cт. } \\
\text { откג. } \\
\text { Stan- } \\
\text { dard } \\
\text { devi- } \\
\text { ation }\end{array}$ & $\begin{array}{c}\text { Аисп. } \\
\text { Disper- } \\
\text { sion }\end{array}$ & \\
\hline $\begin{array}{l}\text { Позитивные } \\
\text { отношения } \\
\text { с окружаю- } \\
\text { щими } \\
\text { Positive relations } \\
\text { with others }\end{array}$ & 54,80 & 7,36 & 135,2 & 74,0 & 7,05 & 125,6 & $10,6^{* *}$ \\
\hline $\begin{array}{l}\text { Автономия } \\
\text { Autonomy }\end{array}$ & 52,55 & 7,34 & 60,1 & 68,9 & 7,88 & 69,0 & $8,33^{* *}$ \\
\hline $\begin{array}{l}\text { Управление } \\
\text { срелой } \\
\text { Managing the } \\
\text { environment }\end{array}$ & 53,92 & 7,13 & 90,4 & 73,3 & 5,90 & 95,8 & $12,3^{* *}$ \\
\hline $\begin{array}{l}\text { Аичностный } \\
\text { рост } \\
\text { Personal growth }\end{array}$ & 55,83 & 6,10 & 30,2 & 69,9 & 7,35 & 54,1 & $37,88^{* *}$ \\
\hline $\begin{array}{l}\text { Цель в жизни } \\
\text { Purpose in life }\end{array}$ & 58,02 & 8,89 & 49,4 & 75,05 & 6,28 & 60,2 & $9,52^{* *}$ \\
\hline $\begin{array}{l}\text { Самопринятие } \\
\text { Self- } \\
\text { acceptance }\end{array}$ & 52,73 & 8,50 & 66,8 & 71,9 & 7,94 & 43,4 & $9,23^{* *}$ \\
\hline${ }^{*} \mathrm{p} \leq 0,05 ;{ }^{* *} \mathrm{p} \leq$ & & & & & & & \\
\hline
\end{tabular}


Корреляционный анализ на контрольном этапе исследования также демонстрирует перераспределение связей между компонентами жизнестойкости и психологического благополучия (рисунок 3).

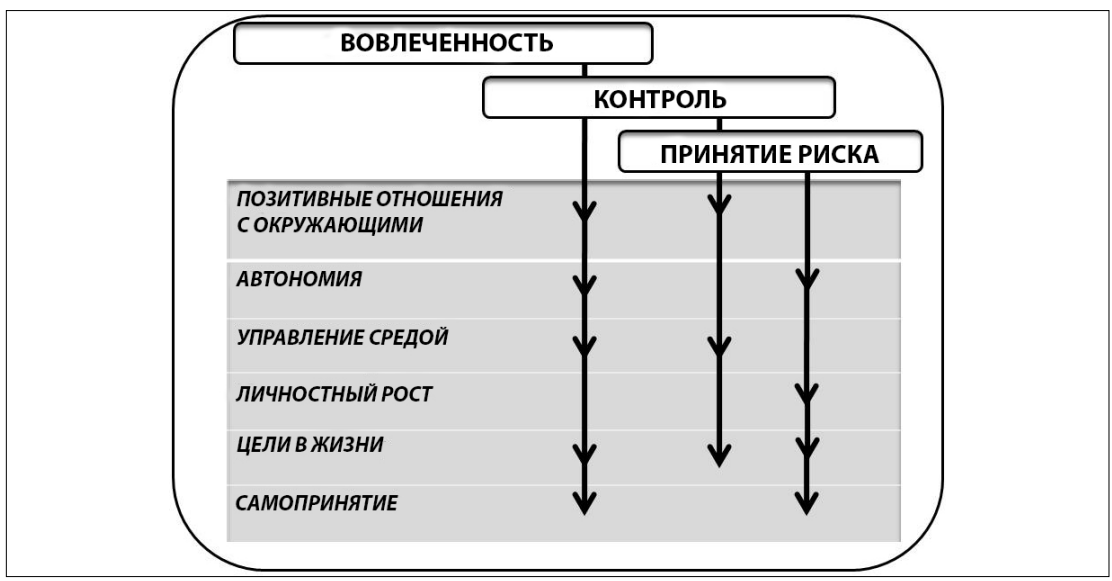

Рисунок 3. Аинамика корреляционных связей межАу компонентами жизнестойкости и психологического благополучия

Figure 3. Dynamics of correlations between the vitality and psychological wellbeing components

Итак, анализ данных контрольных показателей позволяет утверждать, что погружение участников пожилого и старческого возраста в целенаправленную творческую деятельность способствует изменению структуры их взаимодействия с окружением.

Подтверждение вышесказанного отражено в результатах контрольного контент-анализа описаний субъективного восприятия личностной активности, отражающих принятие настоящей реальности как возможность жить полноценной и многомерной жизнью. Так, например, на вопрос «Изменилось ли восприятие времени?» были ответы: «не позволяю себе бездельничать, и увы, много не успеваю»; «да некогда отслеживать, всё время какие-то дела»; «пытаюсь догнать современность», «стараюсь жить в ногу со временем». Изменилась направленность ответов на вопрос: «Что для Вас жизненное счастье?» - «когда мной гордятся родные», «когда младшая дочь приглашает в свою компанию», «покой внутри меня», «давать "прикурить новой поросли"».

Таким образом, мы можем отметить, что участие респондентов в целенаправленной творческой деятельности, в безопасном межличностном взаимодействии в тематических арт-группах стимулирует механизмы 


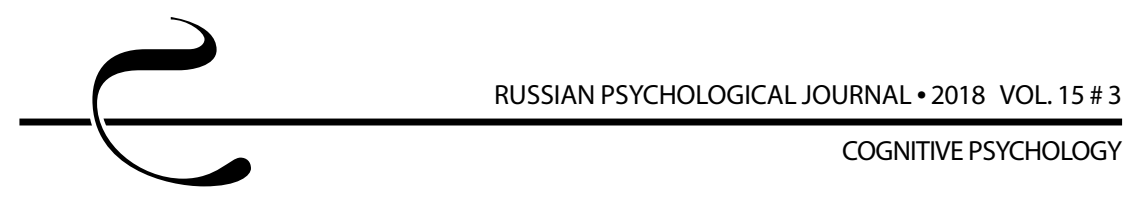

личностной и социальной активности, самостоятельности, независимости и в целом способствует поддержанию уровня психологического благополучия и успешного старения.

\section{Обсуждение результатов}

Ряд исследователей (М. В. Ермолаева; И.Б. Котова, И. В. Гроза; О.Y. Strizhitskaya, E.P. Davedyuk; А. И. Мелёхин) отмечает, что накапливаясь и обогащаясь, жизненный опыт позволяет человеку быть не только объектом жизни, но и ее субъектом [3, 5, 46, 47, 48]. Поэтому уникальный для каждого человека жизненный опыт является специфическим ресурсом его старения. Однако в период позднего онтогенеза использование потенциалов жизненного опыта может быть крайне проблематично. Вероятно, данную ситуацию можно объяснить пониманием (принятием) слабо развитой культуры старения или отсутствием опыта «массового проживания старости» в предыдущих нескольких поколениях, равно как и любого другого периода жизни - детства, отрочества, зрелости $[4,20]$.

Важно, что опыт обладает пластичностью и обратимостью за счет постоянного пересмотра когнитивной и эмоциональной оценок, реинтерпретации результатов конкретных событий или этапов жизни, и как следствие, изменения его структуры [49]. Традиционно первыми показателями уязвимости пожилого возраста считаются ухудшения здоровья и когнитивные изменения. Современные публикации подвергают сомнению обязательные изменения когнитивной сферы как естественную часть старения и предоставляют достоверные факты о ее интактных и патологических вариантах [22, 25, 29]. Сторонники концепции когнитивного резерва предполагают, что возрастные когнитивные нарушения в старости носят не только структурный, но и функциональный характер [50]. Многими исследователями исходный уровень образования, продолжающееся обучение и ориентирование пожилого человека на цели, имеющие для него эмоциональную значимость, рассматриваются как ключевой фактор сохранения когнитивного запаса в старости, и это расширяет представления о компенсаторных возможностях когнитивных функций $[29,48,50]$.

Сохранные когнитивные процессы в пожилом возрасте за счет закрепленных в индивидуальном опыте форм активности могут обеспечивать стабильность системы установок и убеждений человека о себе, мире, отношений с ним, позволяющих успешно реализовать сложившиеся алгоритмы деятельности и препятствовать негативным воздействиям, что, по сути, и есть устойчивый ресурс саморегуляции - жизнестойкость [36, 48, 50, 51]. В.В. Селиванов отмечает, что личности в старости хорошо адаптироваться к возрастным изменениям позволяет сохранная высокая способность к саморегуляции психических функций [52]. 
S. R. Maddi, R.H. Harvey отмечают, что жизнестойкость - это внутренний ресурс, подвластный самому человеку, то, что он может сам изменить и переосмыслить $[53,54]$. Эти положения нашли отражение и в настоящем исследовании, но при интерпретации результатов мы столкнулись с несколькими проблемами. Так, например, многие исследования указывают, что компоненты жизнестойкости развиваются активно в основном в детстве и отчасти в подростковом возрасте, но на последующих этапах онтогенеза их развитие возможно как следствие интенсивного включения в специальные тренинги. В нашем случае тренинг жизнестойкости не являлся целью исследования, и в то же время результат психологической интервенции фиксирует динамику увеличения показателей компонентов жизнестойкости. Данный факт позволяет нам констатировать, что ресурс саморегуляции был достаточно развит на предыдущих возрастных этапах, но для данного возраста слабо востребован и поэтому скорее характеризуется как потенциальный. Для большей части респондентов актуализация данного ресурса стала возможной путем максимального использования интерактивного и целенаправленного погружения в процессы арт-группы [20, 55].

Следующая особенность связана с вопросами нормативных значений используемых тестов, к сожалению, не адаптированных к старческому возрасту. Мы солидарны с публикациями, которые заявляют о существующей проблеме дефицита валидизированных методов для применения в геронтопсихологических исследованиях. Нами использовались нормы авторов методики (до 48 лет), согласно которым у респондентов исследовательской группы в целом результаты соответствуют среднему уровню. По обозначенным выше причинам оценивать полученные данные с позиции предыдущего возрастного периода довольно сложно и скорее некорректно.

В данном исследовании предпринята попытка рассмотреть возможности сохранного когнитивного ресурса с позиции ресурсных стратегий обработки и ревизии событий и, как следствие, обеспечения индивидуальности и уникальности собственного пути. Отражение силы нереализованного жизненного опыта было представлено через призму психологической характеристики жизнестойкости, которая позволяет человеку адаптивно взаимодействовать с окружающей реальностью и детерминирует появление субъективного «чувства личного благополучия» [56, с. 108]. Результаты данного исследования свидетельствуют о том, что сохранение когнитивного ресурса и саморегулирующих способностей (жизнестойкости) личности в старости выступает условием актуализации потенциального жизненного опыта. Эти ресурсы позволяют поддерживать физическое, психологическое и социальное здоровье и обеспечивать ценность и смысл жизни при любых обстоятельствах, что, совершенно очевидно, особо актуально для успешного старения. 


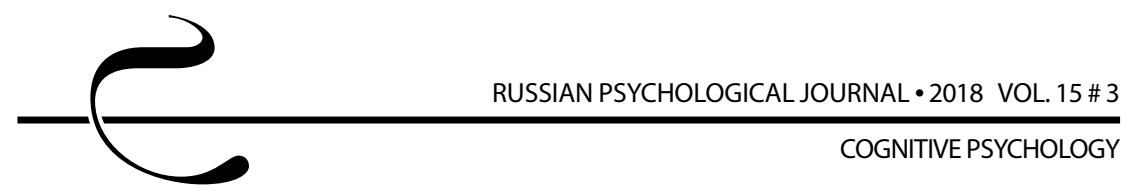

В заключение важно отметить, что представленная работа имеет обоснованные предпосылки и может составить актуальное поле для дальнейшего исследования других ресурсов старения. Мы выражаем надежду, что полученные результаты дают возможность дифференцировать стратегии и способы работы с пожилыми и старыми людьми, а также, что особенно важно в современном обществе, могут быть использованы для просвещения подрастающего поколения с целью формирования уважения к старости и смягчения негативных стереотипов старения.

Статья-победитель конкурса «Российского психологического журнала» - 2018.

\section{Winner of the Russian Psychological Journal contest - 2018.}

\section{Литература}

1. Роик В. Д. Пенсионный возраст и модернизация пенсионных систем: отечественный и зарубежный опыт: монография. М.: Юрайт, 2018. 336 с.

2. Глуханюк Н. С., Гершкович Т. Б. Поздний возраст и стратегии его освоения. Екатеринбург: Изд-во Рос. гос. проф.-пед. ун-та, 2003. 112 с.

3. Ермолаева М. В. Жизненный опыт как критерий личностного развития в старости // Мир психологии. 2007. № 3 (51). С. 145-152.

4. Glozman J., Naumova V. Art-therapy for Mobilizing Personal Resources in the Elderly // Art Therapy: Programs, Uses and Benefits / V. Buchanan (Ed). Nova Science Publishers USA, 2016. P. 113-128.

5. Мелёхин А. И. Качество жизни в пожилом и старческом возрасте: проблемные вопросы // Современная зарубежная психология. 2016. Т. 5, № 1. C. 53-63. DOI: $10.17759 /$ jmfp.2016050107

6. Стрижичкая О. Ю. К вопросу об эмпирическом исследовании геротрансцендентности // Мир Науки. 2017. T. 5, № 6. С. 1-10. URL: https:// mir-nauki. com/PDF/11PSMN617.pdf (дата обращения: 16.08.2018).

7. The Cambridge Handbook of Age and Ageing / M. L. Johnson (Ed.). Cambridge: Cambridge University Press, 2005. 772 p. DOI: $\underline{10.1017 /}$ CBO9780511610714

8. Havighurst R. J. Successful aging // The Gerontologist. 1961. № 1. P. 8-13.

9. Rowe J. W., Kahn R. L. Successful Aging. New York: Random House, Pantheon Books, 1998. 265 p.

10. Stowe J. D., Cooney T. M. Examining Rowe and Kahn's Concept of Successful Aging: Importance of Taking a Life Course Perspective //The Gerontologist. 2015. Vol. 55, Issue 1. P. 43-50. DOI: $10.1093 /$ geront/gnu055

11. Whitley E., Popham F., Benzeval M. Comparison of the Rowe-Kahn Model of Successful Aging With Self-rated Health and Life Satisfaction: The West of 
Scotland Twenty-07 Prospective Cohort Study // The Gerontologist. 2016. Vol. 56, Issue 6. P. 1082-1092. DOI: 10.1093/geront/gnv054

12. Бельцова И. А. Концепция «Успешное старение» как нормативный конструкт в формировании позитивного образа старости в демократическом обществе // Вестник экономики, права и социологии. 2012. № 1. С. 283-288.

13. Шаповаленко И. В. Макартурское исследование успешного старения: на пути к новой геронтологии (реферативный обзор книги Rowe J. W., Kahn R. L. «Successful Aging») // Современная зарубежная психология. 2017. T. 6, № 3. C. 13-21. DOI: 10.17759/jmfp.2017060302

14. Шахматов Н. Ф. Психическое старение: счастливое и болезненное. М.: Медицина, 1996. 304 с.

15. Fernández-Ballesteros R., Kruse A., Zamarrón M. D. \& Caprara M. G. Quality of Life, Life satisfaction and Positive Ageing // GeroPsychology: European Perspectives for an Ageing World / R. Fernández-Ballesteros (Ed.). Göttingen: Hogrefe \& Huber, 2007. P. 196-223.

16. Fernández-Ballesteros R., \& Díez-Nicolás J. Active aging. Mandatory retirement and a barrier // Releasing the Potentials of Senior Scholars and Scientists Emerging Productivity in a New Era / H. A. Becker \& J. J. F. Schroots (Eds.). Amsterdam: ERGO, European Research Institute on Health and Aging, 2008. P. 81-109.

17. Bryant L. L., Corbett K. K., Kutner J. S. In their own words: a model of healthy aging // Social Science \& Medicine. 2001. Vol. 53. P. 927-941.

18. Чуева Е. Н. Психологические условия конструктивного развития личности в период зрелости. Петр.-Камч.: Изд-во КамГу, 2005. 186 с.

19. Сурикова Я. А. Особенности временной перспективы пожилых, проживающих в условиях социальной изоляции // Вестник КРАУНЦ. Серия «Гуманитарные науки». 2011. № 2 (18). С. 90-97.

20. Наумова В. А. Оптимизация личностных ресурсов на этапе поздней зрелости. Петр.-Камч.: Изд-во КамГУ им. Витуса Беринга, 2014. 284 с.

21. Альмуканов К. Г. Благополучное старение: ретроспективный анализ и современное состояние // Фундаментальные исследования. 2014. № 8. C. 212-216. URL: https://fundamental-research.ru/ru/article/view?id=34537 (дата обращения: 26.08.2018).

22. Стрижицкая О. Ю. Самодетерминация в период поздней взрослости и старения: теоретические подходы и проблемы // Вестник СанктПетербургского университета. Серия 12: Психология. Социология. Педагогика. 2013. № 4. С. 118-127.

23. Головей Л. А., Стрижицкая О. Ю., Криулина А. В. Позитивное функционирование личности в пожилом возрасте: комплексный подход // Пси- 


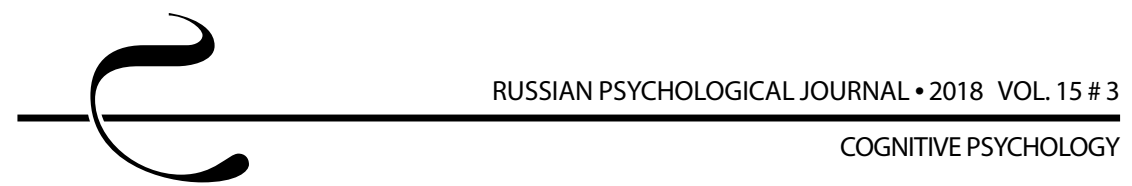

хологические исследования. 2014. T. 7, № 36. С. 9. URL: http://psystudy. ru/index.php/num/2014v7n36/1020-golovey36.html (дата обращения 26.08.2018).

24. Strizhitskaya O. Aging in Russia // The Gerontologist. 2016. Vol. 56, Issue 5. P. 795-799.

25. Леонтьев Д. А. Саморегуляция, ресурсы и личностный потенциал // Сибирский психологический журнал. 2016. № 62. С. 18-37. DOI: $10.17223 /$ $17267080 / 62 / 3$

26. Александрова М. Д. Проблемы социальной и психологической геронтологии. Л.: Изд-во ЛГУ, 1974. 135 с.

27. Ананьев Б. Г. Человек как предмет познания. 3-е изд. СПб.: Питер, 2001. $288 \mathrm{c}$.

28. Stern Y. Cognitive reserve // Neuropsychologia. 2009. Vol. 47, Issue 10. P. 2015-2028. DOI: 10.1016/j.neuropsychologia.2009.03.004

29. Стрижицкая О. Ю. Когнитивный резерв как психологический и психофизиологический ресурс в период старения // Вестник СанктПетербургского университета. Серия 16. 2016. Вып. 2. С. 79-87. DOI: 10.21638/11701/spbu16.2016.209

30. Cho J., Martin P., Poon L. W. Successful Aging and Subjective Well-Being Among Oldest-Old Adults // The Gerontologist. 2015. Vol. 55, Issue 1. P. 132-143. DOI: $10.1093 /$ geront/gnu074

31. Татенко В. О. Субъект психической активности: поиск новой парадигмы // Психологический журнал. 1995. Т. 16, № 3. С. 23-34.

32. Бодалев А. А. Акме - эффект личностного осуществления в процессе социализации и индивидуализации взрослого человека // Мир психологии. 1998. № 1. С. 59-66.

33. Erikson E. H. The Life Cycle Completed. N. Y., 1982. 108 p.

34. Даведюк Е. П. Самодетерминация и ее индивидуальные проявления в пожилом возрасте // Вестник Санкт-Петербургского университета. Cер. 16. 2014. Вып. 2. С. 51-57.

35. Deci E. L., Vansteenkiste M. Self-determination theory and basic need satisfaction: Understanding human development in positive psychology // Ricerche di Psichologia. 2004. Vol. 27, № 1. P. 23-40.

36. Леонтьев Д. А. Новые ориентиры понимания личности в психологии: от необходимого к возможному // Личностный потенциал: структура и диагностика / под ред. Д. А. Леонтьева. М.: Смысл, 2011. С. 12-41.

37. Корсакова Н. К., Балашова Е. Ю., Рощина И. Ф. Экспресс-методика оценки когнитивных функций при старении // Психологические исследования. 2009. № 3 (5). URL: http://psystudy.ru/num/2009n3-5/176-korsakova5 (дата обращения: 30.07.2018). 
38. Анцыферова Л. И. Психология старости: особенности развития психологии личности в период поздней взрослости // Психологический журнал. 2001. Т. 22, № 3. С. 86-99.

39. Леонтьев Д. А., Рассказова Е. И. Тест жизнестойкости. М.: Смысл, 2006. 63 с.

40. Шевеленкова Т. Д., Фесенко Т. П. Психологическое благополучие личности // Психологическая диагностика. 2005. № 3. С. 95-121.

41. Копытин А. И. Системная арт-терапия: теоретическое обоснование, методология применения, лечебно-реабилитационные и дестигматизирующие эффекты: дисс. ... д. мед. наук. СПб., 2010. 311 с.

42. Выготский Л. С. Развитие высших психических функций. М.: Изд-во АПН РСФСР, $1960.500 \mathrm{C}$.

43. Элькин В. М. Театр цвета и мелодии Ваших страстей. Цветовая психология и психотерапия шедеврами искусства. Гармонизация цветовых программ жизни и Ваши тайные способности. СПб.: ИД «Петрополис», 2005. 292 с.

44. Копытин А. И., Платтс Дж. Руководство по фототерапии. М.: КогитоЦентр, 2009. 184 c.

45. Копытин А. И., Корт Б. Техники телесно-ориентированной арт-терапии. М.: Психотерапия, 2011. 128 с.

46. Котова И. Б., Гроза И. В. Жизненный ресурс личности как психологическое условие позитивного мироощущения // Прикладная психология и психоанализ. 2012. № 2. С. 6.

47. Strizhitskaya O. Y., DavedyukE. P. Self-Determination Structure in Aging: From Theory to Practice // Proceedings of the 3rd Annual International Conference on Cognitive and Behavioral Psychology (CBP 2014). Singapore, 2014. P. 56-59.

48. Мелёхин А. И. Модель психического: траектория изменений в пожилом и старческом возрасте // Консультативная психология и психотерапия. 2016. T. 24, № 1. C. 24-43. DOI: 10.17759/срр.2016240103

49. Шмидт В. В. Периодизация психического развития в методологии психологического исследования // Психология зрелости и старения. 2002. № 1 (17). С. 6-17.

50. Barulli D., Stern Y. Efficiency, capacity, compensation, maintenance, plasticity: emerging concepts in cognitive reserve //Trends in Cognitive Sciences. 2013. Vol. 17, Issue 10. P. 502-509. DOI: $10.1016 /$ j.tics.2013.08.012

51. Calasanti T. Combating Ageism: How Successful Is Successful Aging? // The Gerontologist. 2016. Vol. 56, Issue 6. P. 1093-1101.DOI:10.1093/geront/gnv076

52. Селиванов В. В. Мышление в личностном развитии субъекта. Смоленск: Универсум, 2003. 311 с.

53. Maddi S. R. The personality construct of hardiness: I. Effects on experiencing, coping, and strain // Consulting Psychology Journal: Practice and Research. 1999. Vol. 51 (2). P. 83-94. DOI: 10.1037/1061-4087.51.2.83 
54. Maddi S. R., Harvey R. H. Hardiness Considered Across Cultures // Handbook of Multicultural Perspectives on Stress and Coping. N. Y: Springer, 2006. P. 409-426.

55. Балл Г. А. Психологическое содержание личностной свободы: сущность и составляющие // Психологический журнал. 1997. Т. 18, № 5. C. 7-19.

56. Эммонс Р. Психология высших устремлений. Мотивация и духовность личности. М.: Смысл, 2004. 416 с.

\section{References}

1. Roik V.D. Pensionnyi vozrast imodernizatsiya pensionnykh sistem: otechestvennyi i zarubezhnyi opyt: monografiya [Retirement age and modernisation of pension systems: Domestic and foreign experience]. Moscow, Yurait Publ., 2018. 336 p.

2. Glukhanyuk N. S., Gershkovich T. B. Pozdnii vozrast i strategii ego osvoeniya [Late age and the strategy of its development]. Ekaterinburg, Russian State Vocational Pedagogical University Publ., 2003. 112 p.

3. Ermolaeva M. V. Life experience as a criterion for personal development in the elderly. Mir psikhologii - World of Psychology, 2007, no. 3 (51), pp. 145-152 (in Russian).

4. Glozman J., Naumova V. Art-therapy for mobilizing personal resources in the elderly. In: Buchanan V. (ed.) Art therapy: Programs, uses and benefits. Nova Science Publishers USA, 2016, pp. 113-128.

5. Melekhin A. I. Quality of life in the elderly and senile age: Problematic issues. Sovremennaya zarubezhnaya psikhologiya - Modern Foreign Psychology, 2016, V. 5, no. 1, pp. 53-63 (in Russian). DOI: 10.17759 /jmfp. 2016050107

6. Strizhitskaya O. Yu. Approaches to empirical study of gerotranscendence. Mir Nauki - World of Science, 2017, V. 5, no. 6, pp. 1-10 (in Russian). Available at: https://mir-nauki.com/PDF/11PSMN617.pdf (Accessed 16 August 2018).

7. Johnson M. L. (ed.) The Cambridge handbook of age and ageing. Cambridge, Cambridge University Press, 2005. 772 p. DOI: $10.1017 /$ CBO9780511610714

8. Havighurst R. J. Successful aging. The Gerontologist, 1961, no. 1, pp. 8-13.

9. Rowe J.W., Kahn R. L. Successful aging. New York, Random House, Pantheon Books, 1998. 265 p.

10. Stowe J. D., Cooney T. M. Examining Rowe and Kahn's concept of successful aging: Importance of taking a life course perspective. The Gerontologist, 2015, V. 55, Issue 1, pp. 43-50. DOI: 10.1093/geront/gnu055

11. Whitley E., Popham F., Benzeval M. Comparison of the Rowe-Kahn model of successful aging with self-rated health and life satisfaction: The West of 
Scotland twenty-07 prospective cohort study. The Gerontologist, 2016. V. 56, Issue 6, pp. 1082-1092. DOI: 10.1093/geront/gnv054

12. Bel'tsova I. A. The 'successful aging' concept as a normative construct for a positive image of old age in a democratic society. Vestnik ekonomiki, prava i sotsiologii - Bulletin of Economics, Law and Sociology, 2012, no. 1, pp. 283-288 (in Russian).

13. Shapovalenko I.V. MacArthur study of successful aging: on the way to a new gerontology: Abstract review of the Successful Aging book by Rowe J.W. and Kahn R. L. Journal of Modern Foreign Psychology, 2017, V. 6, no. 3, pp. 13-21 (in Russian). DOI: 10.17759/jmfp.2017060302

14. Shakhmatov N. F. Psikhicheskoe starenie: schastlivoe i boleznennoe [Mental aging: Happy and painful]. Moscow, Meditsina Publ., 1996. 304 p.

15. Fernández-Ballesteros R., Kruse A., Zamarrón M. D. \& Caprara M. G. Quality of life, life satisfaction and positive ageing. In: Fernández-Ballesteros R. (ed.) GeroPsychology: European perspectives for an ageing world. Göttingen, Hogrefe \& Huber, 2007, pp. 196-223.

16. Fernández-Ballesteros R., \& Díez-Nicolás J. Active aging. Mandatory retirement and a barrier. In: Becker H. A. \& Schroots J. J. F. (eds.) Releasing the potentials of senior scholars and scientists emerging productivity in a new era. Amsterdam, ERGO, European Research Institute on Health and Aging, 2008, pp. 81-109.

17. Bryant L. L., Corbett K. K., Kutner J. S. In their own words: a model of healthy aging. Social Science \& Medicine, 2001, V. 53, pp. 927-941.

18. Chueva E. N. Psikhologicheskie usloviya konstruktivnogo razvitiya lichnosti $v$ period zrelosti [Psychological conditions of personal constructive development in the period of maturity]. Petropavlovsk-Kamchatskiy, Kamchatka State University Publ, 2005. 186 p.

19. Surikova Ya. A. Characteristics of time perspective in the elderly living under conditions of social exclusion. Seriya "Gumanitarnye nauki" - Bulletin of Kamchatka Regional Association "Educational-Scientific Center": Series Humanities, 2011, no. 2 (18), pp. 90-97 (in Russian).

20. Naumova V. A. Optimizatsiya lichnostnykh resursov na etape pozdnei zrelosti [Optimization of personal resources in late maturity]. PetropavlovskKamchatskiy, Kamchatka State University Publ, 2014. 284 p.

21. Al'mukanov K. G. Successful aging: A retrospective analysis and current state. Fundamental'nye issledovaniya - Fundamental Research, 2014, no. 8, pp. 212-216 (in Russian). Available at: https://fundamental-research.ru/ru/ article/view?id=34537 (Accessed 26 August 2018).

22. Strizhitskaya O. Yu. Self-determination in late adulthood and aging: Theoretical approaches and problems. Vestnik Sankt-Peterburgskogo universiteta. Seriya 12: Psikhologiya. Sotsiologiya. Pedagogika - Bulletin of 
St. Petersburg University. Series 12: Psychology. Sociology. Pedagogics, 2013, no. 4, pp. 118-127 (in Russian).

23. Golovei L. A., Strizhitskaya O. Yu., Kriulina A. V. Positive functioning of personality in the elderly: A comprehensive approach. Psychological Studies, 2014, V. 7, no. 36, p. 9 (in Russian). Available at: http://psystudy.ru/index. php/num/2014v7n36/1020-golovey36.html (Accessed 26 August 2018).

24. Strizhitskaya O. Aging in Russia. The Gerontologist, 2016, V. 56, Issue 5, pp. 795-799.

25. Leont'ev D. A. Self-regulation, resources, and personal potential. Sibirskii psikhologicheskii zhurnal - Siberian Psychological Journal, 2016, no. 62, pp. 18-37 (in Russian). DOI: 10.17223/17267080/62/3

26. Aleksandrova M. D. Problemy sotsial'noi i psikhologicheskoigerontologii [lssues of social and psychological gerontology]. Leningrad, LSU Publ., 1974. 135 p.

27. Anan'ev B. G. Chelovek kak predmet poznaniya [Man as an object of knowledge]. St. Petersburg, Piter Publ., 2001. 288 p.

28. Stern Y. Cognitive reserve. Neuropsychologia, 2009, V. 47, Issue 10, pp. 20152028. DOI: $10.1016 /$ j.neuropsychologia.2009.03.004

29. Strizhitskaya O. Yu. Cognitive reserve as a psychological and psychophysiological resource in aging. Vestnik Sankt-Peterburgskogo universiteta. Seriya 16 - Bulletin of St. Petersburg University: Series 12, 2016, V. 2, pp. 79-87 (in Russian). DOI: 10.21638/11701/spbu16.2016.209

30. Cho J., Martin P., Poon L. W. Successful aging and subjective well-being among oldest-old adults. The Gerontologist, 2015, V. 55, Issue 1, pp. 132-143. DOI: $10.1093 /$ geront/gnu074

31. Tatenko V. O. A subject of mental activity: Search for a new paradigm. Psikhologicheskii zhurnal, 1995, V. 16, no. 3, pp. 23-34 (in Russian).

32. Bodalev A. A. Akme as an effect of personal realization in adults' socialization and individualization. Mir psikhologii-World of Psychology, 1998, no. 1, pp. 59-66 (in Russian).

33. Erikson E. H. The life cycle completed. N. Y., 1982. 108 p.

34. Davedyuk E. P. Self-determination and its individual manifestations in the elderly. Vestnik Sankt-Peterburgskogo universiteta. Ser. 16-Bulletin of St. Petersburg University: Series 16, 2014, V. 2, pp. 51-57 (in Russian).

35. Deci E. L., Vansteenkiste M. Self-determination theory and basic need satisfaction: Understanding human development in positive psychology. Ricerche di Psichologia, 2004, V. 27, no. 1, pp. 23-40.

36. Leont'ev D. A. New reference points for understanding personality in psychology: From the necessary towards the possible. In: Leont'ev D. A. Lichnostnyi potentsial: struktura i diagnostika [Personal potential: Structure and diagnosis]. Moscow, Smysl Publ., 2011, pp. 12-41. 
37. Korsakova N. K., Balashova E. Yu., Roshchina I. F. Express-method of assessment of cognitive functions in aging. Psychological Studies, 2009, no. 3 (5) (in Russian). Available at: http://psystudy.ru/num/2009n3-5/176-korsakova5 (Accessed 30 June 2018).

38. Antsyferova L. I. Psychology of ageing: Fatures of development of personality in late adulthood. Psikhologicheskii zhurnal, 2001, V. 22, no. 3, pp. 86-99 (in Russian).

39. Leont'ev D. A., Rasskazova E. I. Test zhiznestoikosti [Resilience test]. Moscow, Smysl Publ., 2006. 63 p.

40. Shevelenkova T. D., Fesenko T. P. Psychological well-being of personality. Psikhologicheskaya diagnostika - Psychological Diagnostics, 2005, no. 3, pp. 95-121 (in Russian).

41. Kopytin A. I. Sistemnaya art-terapiya: teoreticheskoe obosnovanie, metodologiya primeneniya, lechebno-reabilitatsionnye i destigmatiziruyushchie effekty [Systems art therapy: theoretical basis, methodology of application, therapeutic, rehabilitation and destigmatising effects]. Diss. Dr. Sci. (Med.). St. Petersburg, 2010. 311 p.

42. Vygotskii L. S. Razvitie vysshikh psikhicheskikh funktsii [Development of higher mental functions]. Moscow, APN RSFSR Publ., 1960. 500 p.

43. El'kin V. M. Teatr tsveta i melodii Vashikh strastei. Tsvetovaya psikhologiya i psikhoterapiya shedevrami iskusstva. Garmonizatsiya tsvetovykh programm zhizni i Vashi tainye sposobnosti [Theatre of color and melodies of your passions: Color psychology and psychotherapy by means of art masterpieces: Harmonization of color programs of life and your secret abilities]. St. Petersburg, Petropolis Publ., 2005. 292 p.

44. Kopytin A. I., Platts Dzh. Rukovodstvo po fototerapii [A guide to phototherapy]. Moscow, Kogito-Tsentr Publ., 2009. 184 p.

45. Kopytin A. I., Kort B. Tekhniki telesno-orientirovannoi art-terapii [Techniques of body-oriented art therapy]. Moscow, Psikhoterapiya Publ., 2011. 128 p.

46. Kotova I. B., Groza I. V. Personal life resource as a psychological condition of a positive outlook. Prikladnaya psikhologiya i psikhoanaliz-Applied Psychology and Psychoanalysis, 2012, no. 2, p. 6 (in Russian).

47. Strizhitskaya O. Y., Davedyuk E. P. Self-determination structure in aging: From theory to practice. Proceedings of the 3rd Annual International Conference on Cognitive and Behavioral Psychology (CBP 2014). Singapore, 2014, pp. 56-59.

48. Melekhin A. I. Model of the mental: Trajectory of changes in elderly and senile age. Konsul'tativnaya psikhologiya i psikhoterapiya - Counseling Psychology and Psychotherapy, 2016, V. 24, no. 1, pp. 24-43 (in Russian). DOI: $\underline{10.17759 / \text { cpp.2016240103 }}$ 
49. Shmidt V. V. Periodization of mental development in the methodology of psychological research. Psikhologiya zrelosti i stareniya - Psychology of Maturity and Aging, 2002, no. 1 (17), pp. 6-17 (in Russian).

50. Barulli D., Stern Y. Efficiency, capacity, compensation, maintenance, plasticity: emerging concepts in cognitive reserve. Trends in Cognitive Sciences, 2013, V. 17, Issue 10, pp. 502-509. DOI: 10.1016/j.tics.2013.08.012

51. Calasanti T. Combating ageism: How successful is successful aging? The Gerontologist, 2016, V. 56, Issue 6, pp. 1093-1101.DOI: 10.1093/geront/gnv076

52. Selivanov V.V. Myshlenie v lichnostnom razvitii sub"ekta [Thinking in personal development of the subject]. Smolensk, Universum Publ., 2003. 311 p.

53. Maddi S. R. The personality construct of hardiness: I. Effects on experiencing, coping, and strain. Consulting Psychology Journal: Practice and Research, 1999, V. 51 (2), pp. 83-94. DOI: 10.1037/1061-4087.51.2.83

54. Maddi S. R., Harvey R. H. Hardiness considered across cultures. In: Handbook of multicultural perspectives on stress and coping. N. Y, Springer, 2006, pp. 409-426.

55. Ball G. A. Psychological content of personal freedom: Essence and components. Psikhologicheskii zhurnal, 1997, V. 18, no. 5, pp. 7-19 (in Russian).

56. Emmons R. The psychology of ultimate concerns: Motivation and spirituality in personality. New York, Guilford Press, 1999 (Russ. ed.: Emmons R. Psikhologiya vysshikh ustremlenii. Motivatsiya idukhovnost'lichnosti. Moscow, 2004.416 p.). 